\title{
Analisis Layanan Sistem Informasi Akademik Perguruan Tinggi Berbasiskan Fuzzy Service Quality
}

\section{(Analysis of Higher Education Academic Information System Services Based on Fuzzy Service Quality)}

\author{
I.G.P. Asto Buditjahjanto ${ }^{1}$
}

\begin{abstract}
A higher education institution as an organization that offers academic information system services must be able to analyze their academic information system services. To analyze academic information system services, higher education institution must be able to measure the gap between perceptions and expectations of the users. The analysis is carried out on the five dimensions of service quality (Servqual) and its indicators so that each gap can be identified whether positive or negative. Fuzzy service quality method is used in this study because it can eliminate inconsistencies, uncertainties, and inadequacy in assessing an existing problem in academic information system. The results show that all gap values in the service quality dimension show negative signs. This shows that the services provided do not meet user's expectations. Therefore, it needs improvement for those services. The highest gap in the dimension of service quality is reliability at -1.010 , followed by responsiveness at $\mathbf{- 0 . 9 0 6}$, assurance at $\mathbf{- 0 . 8 3 1}$, empathy at $\mathbf{- 0 . 7 0 3}$, and tangibility at $\mathbf{- 0 . 6 8 5}$.
\end{abstract}

Intisari-Perguruan tinggi sebagai suatu organisasi yang menawarkan layanan sistem informasi akademik harus dapat dianalisis layanan sistem informasi akademiknya. Untuk menganalisis layanan sistem informasi akademiknya, perguruan tinggi harus dapat mengukur gap antara persepsi dan ekspektasi pengguna, dalam hal ini mahasiswa. Analisis dilakukan pada kelima dimensi service quality (Servqual) melalui indikatorindikatornya sehingga dapat diketahui masing-masing gap yang terjadi, bernilai positif atau negatif. Metode fuzzy service quality digunakan pada makalah ini karena mempunyai kemampuan dalam menghilangkan ketidakkonsistenan, ketidakyakinan, dan ketidakcukupan dalam menilai suatu masalah yang ada pada sistem informasi akademik. Hasil menunjukkan bahwa seluruh nilai gap pada dimensi service quality menunjukkan tanda negatif. Hal ini menunjukkan bahwa layanan yang disediakan masih belum memenuhi ekspektasi para pengguna. Oleh karena itu, diperlukan peningkatan layanan tersebut pada masingmasing dimensi pada service quality. Nilai gap pada dimensi service quality yang tertinggi adalah pada dimensi reliability,

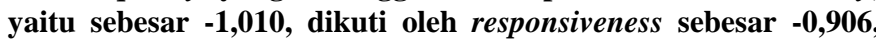

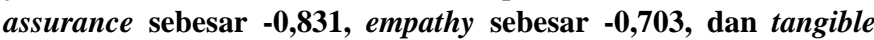
sebesar $\mathbf{- 0 , 6 8 5}$.

Kata Kunci-Fuzzy Service Quality, Persepsi Pengguna, Ekspektasi Pengguna, Nilai Gap, Sistem Informasi Akademik, Quality Improvement.

\footnotetext{
${ }^{1}$ Jurusan Teknik Elektro, Fakultas Teknik, Universitas Negeri Surabaya, Kampus Ketintang, Surabaya, INDONESIA (e-mail: asto@unesa.ac.id)
}

\section{Pendahuluan}

Perguruan tinggi adalah suatu organisasi atau lembaga yang mendidik mahasiswa dan menghasilkan lulusan dengan kemampuan dan kompetensi yang baik. Sebagai lembaga yang menghasilkan lulusan dengan kualifikasi yang baik, perguruan tinggi harus mampu mengelolah layanan-layanan yang ada pada perguruan tinggi tersebut dengan baik. Layanan yang baik yang diberikan kepada pengguna dapat menyebabkan terpenuhinya harapan atau ekspektasi pengguna. Pengguna layanan perguruan tinggi antara lain mahasiswa, dosen, karyawan, dan masyarakat pengguna lulusan. Porsi terbesar dari pengguna layanan tersebut adalah mahasiswa. Untuk itu, diperlukan usaha dalam rangka meningkatkan nilai layanan melalui upaya perbaikan terus-menerus dengan memfokuskan pada kepentingan untuk memenuhi ekspektasi dari pengguna layanan.

Layanan perguruan tinggi berbentuk antara lain layanan sistem informasi akademik, layanan perpustakaan, layanan bahasa Inggris, layanan fasilitas olahraga, dan layanan kesehatan. Perguruan tinggi yang merupakan suatu organisasi yang menawarkan layanan seharusnya dapat memenuhi layanan yang diharapkan atau ekspektasi dari pengguna. Layanan yang baik adalah apabila gap antara layanan yang dirasakan atau persepsi pengguna dengan ekspektasi pengguna minimal tidak berbeda. Jika masih ada perbedaan dengan nilai gap yang bernilai negatif antara persepsi dengan ekspektasi, maka diperlukan perbaikan terhadap layanan tersebut. Begitu pula sebaliknya jika nilai gap bernilai positif, maka layanan tersebut harus tetap dipertahankan.

Mahasiswa merupakan pengguna terbesar dalam merasakan layanan suatu perguruan tinggi. Kepuasan mahasiswa sering digunakan untuk menilai kualitas suatu pendidikan di suatu perguruan tinggi. Oleh karena itu, kualitas layanan dalam pendidikan dapat dikatakan ditentukan oleh dapat terpenuhinya persepsi dan ekspektasi mahasiswa. Diperlukan cara atau metode untuk mengukur layanan tersebut sehingga dapat diketahui layanan tersebut sudah baik atau belum. Berbagai konsep dan model telah dikembangkan untuk mengetahui kepuasan pengguna terhadap suatu layanan. Service quality atau sering disingkat dengan Servqual adalah suatu metode atau cara untuk mengevaluasi suatu kualitas layanan pada suatu organisasi serta dapat digunakan untuk mengukur tingkat kepuasan pelanggan. Service quality merupakan metode yang unggul dalam menganalisis perbedaan persepsi dan ekspektasi dari suatu layanan yang dirasakan pengguna [1]. Service quality menguji lima dimensi 
kualitas layanan, yaitu daya tanggap (responsiveness), jaminan (assurance), empati (empathy), berwujud (tangible), dan keandalan (reliability). Setiap dimensi merupakan ukuran kualitas layanan baik persepsi dan harapan. Beberapa penggunaan service quality dalam suatu organisasi antara lain service quality dapat digunakan untuk memahami tingkat kesenjangan yang ada antara harapan dan persepsi di antara pelanggan perbankan dalam konten kualitas layanan [2]-[4]. Pada bidang kesehatan, service quality digunakan untuk mengevaluasi kepuasan pasien terhadap kualitas layanan kesehatan rumah sakit [5], [6]. Hasil penelitiannya dapat menunjukkan atribut dari service quality yang mempunyai level kepuasan yang tinggi dari konsumen dan atribut yang mempunyai level kepuasan yang rendah. Pada bidang perhotelan, service quality dapat digunakan untuk mengukur kualitas manajemen hotel terhadap persepsi dan ekspektasi dari pelanggan [7], [8]. Dengan diketahuinya gap, dapat dilakukan perbaikan untuk meningkatkan kualitas manajemen hotel. Selain itu, service quality juga dapat digunakan pada layanan transportasi [9], [10], layanan kebugaran [11], dan layanan perpustakaan [12]. Masih sedikit penelitian yang terkait dengan layanan pada pendidikan tinggi yang menggunakan service quality. Referensi [13] menggunakan service quality untuk memodelkan layanan perguruan tinggi dan mengukur korelasinya dari masing-masing construct modelnya, sedangkan pada penelitian lain, studi literatur dilakukan terhadap kemampuan akademik siswa laki-laki dan perempuan ditinjau dari ketersediaan kualitas layanan pendidikan [14].

Makalah ini fokus pada layanan sistem informasi akademik yang ada pada sebuah Perguruan Tinggi Negeri (PTN) di Surabaya. Permasalahan yang muncul adalah belum terukurnya perbedaan (gap) antara persepsi dan ekspektasi mahasiswa terhadap layanan sistem informasi akademik PTN tersebut, ditinjau dari lima dimensi service quality. Selama ini identifikasi perbaikan layanan hanya berdasarkan kotak saran dan keluhan langsung dari mahasiswa dalam menggunakan layanan sistem informasi akademik, sehingga perbaikan layanan belum terencana dengan baik karena tidak dilakukan identifikasi layanan berdasarkan lima dimensi service quality dan indikatornya dalam menentukan layanan yang tidak bagus, sehingga dapat ditentukan besar usaha yang dilakukan untuk memperbaiki layanan tersebut.

Pada permasalahan penilaian kualitatif seperti pada penilaian service quality, terdapat kemungkinan terjadi ketidakkonsistenan, ketidakyakinan, dan ketidakcukupan penampilan/kemunculan permasalahan dalam penilaian. Hal ini terjadi karena adanya ketergantungan terhadap variabelvariabel lingusitik [15]. Penelitian yang telah dilakukan hanya menggunakan skala satu sampai dengan skala lima dalam mengukur level dimensi dari service quality [4], [5]. Diperlukan skala yang lebih banyak agar responden lebih akurat dalam menentukan preferensi terhadap suatu item indikator. Kelemahan dari metode service quality adalah responden hanya menentukan preferensinya berdasarkan angka. Representasi penilaian dalam bentuk angka dapat menyebabkan permasalahan dalam melakukan penilaian berdasarkan preferensi responden secara akurat [16]. Untuk mengatasi permasalahan tersebut, makalah ini menggunakan metode fuzzy pada service quality. Fuzzy mempunyai kemampuan dalam menghilangkan ketidakkonsistenan, ketidakyakinan, dan ketidakcukupan dalam menilai suatu masalah [17]-[19].

Makalah ini menggunakan fuzzy service quality untuk menghitung besar gap antara persepsi dan ekspektasi dari mahasiswa terhadap penggunaan sistem informasi akademik. Makalah ini juga mengembangkan instrumen kuesioner dalam mengakses kelima dimensi service quality dengan menggunakan fuzzy linguistic dengan tujuh kategori. Makalah ini bertujuan menganalisis gap antara persepsi dan ekspektasi pada layanan sistem informasi akademik suatu PTN di Surabaya berbasiskan metode fuzzy service quality. Analisis dilakukan pada kelima dimensi service quality melalui indikator-indikatornya, sehingga dapat diketahui masingmasing gap yang terjadi, bernilai positif atau negatif. Diketahuinya nilai gap, positif atau negatif, dapat digunakan sebagai dasar dalam melaksanakan quality improvement dari sistem informasi akademik PTN tersebut.

Keterbaruan dalam makalah ini adalah menggabungkan metode fuzzy dan service quality menggunakan tujuh level preferensi untuk menganalisis permasalahan layanan sistem informasi pada perguruan tinggi. Kontribusi makalah ini berupa pengetahuan penggunaan fuzzy service quality terhadap tingkat layanan sistem informasi pada suatu PTN di Surabaya dan pengembangan instrumen kuesioner dalam mengakses kelima dimensi service quality dengan menggunakan fuzzy lingusitic dengan menggunakan preferensi tujuh tingkatan.

\section{FUZZY SERVICE QUALITY}

Fuzzy digunakan pada service quality untuk mengatasi kendala penerjemahan preferensi responden terhadap pengisian kuesioner. Seperti diketahui, penilaian seseorang seringkali tidak jelas dan tidak mudah bagi orang tersebut untuk mengungkapkan bobot kriteria evaluasi dan kepuasan terhadap kualitas layanan suatu organisasi atau perusahaan dengan menggunakan nilai numerik yang tepat. Oleh karena itu, diperlukan suatu cara yang dapat lebih dipahami seseorang dalam memberikan penilaian. Penilaian yang lebih realistis adalah penilaian dengan menggunakan istilah linguistik untuk menggambarkan nilai ekspektasi, nilai persepsi, dan bobot penting kriteria evaluasi. Data evaluasi subjektif dapat diekspresikan secara lebih memadai dalam variabel linguistik. Fuzzy mempunyai kemampuan dalam menggunakan penilaian secara linguistik. Fuzzy juga banyak digunakan untuk penilaian service quality pada perusahaan. Penggunaan fuzzy service quality dapat membantu evaluator dalam memberikan penilaian suatu atribut pada kuesioner yang sulit untuk memberikan penilaian berdasarkan numerik tetapi lebih mudah jika menggunakan variabel linguistik [17]. Referensi [18] menyatakan bahwa karena ketidakjelasan yang ada dalam evaluasi kualitas layanan maskapai, teori himpunan fuzzy adalah metode yang tepat untuk menghadapi ketidakpastian tersebut. Untuk memberikan layanan yang 


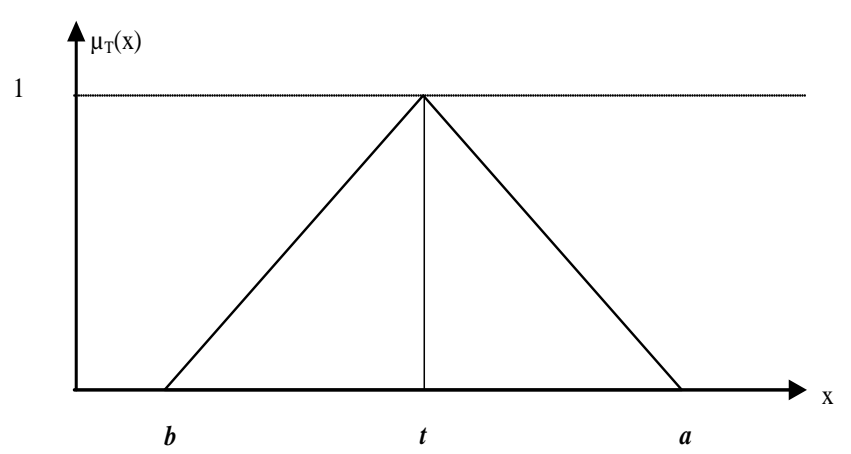

Gbr. 1 Triangular Fuzzy Number (TFN).

optimal, fuzzy service quality dapat digunakan pada sektor layanan perbankan. Penelitiannya merekomendasikan bagi perusahaan untuk mempertimbangkan persepsi pasien tentang kualitas layanan [19]. Fuzzy mempunyai beberapa bentuk model perhitungan keanggotaannya. Salah satu yang sering digunakan adalah Triangular Fuzzy Number (TFN). TFN mempunyai keunggulan karena kemudahannya dalam aplikasi penggunaan dalam penilaian sesuatu [16]. Sebagai contoh, jika $T$ adalah suatu bilangan fuzzy, maka persamaan untuk menentukan tingkatan fungsi keanggotaannya dalam bentuk TFN adalah seperti pada (1).

$$
\mu_{T}=\left\{\begin{array}{l}
\frac{x-b}{t-b}, \text { jika } b \ll x \ll t ; \\
\frac{a-x}{a-t}, \text { jika } t \ll x \ll a ; \\
0 \quad \text { yang lainnya. }
\end{array}\right.
$$

dengan $b$ adalah nilai bawah, $t$ adalah nilai tengah, dan $a$ adalah nilai atas dari $T$ yang berupa bilangan fuzzy. Gbr. 1 menunjukkan bentuk TFN dari bilangan fuzzy dari $T$.

Untuk merepresentasikan defuzzied suatu variabel bilangan fuzzy dapat digunakan graded mean integration seperti pada (2) [20].

$$
P(T)=\frac{1}{6}(b+4 t+a)
$$

Bilangan fuzzy mempunyai beberapa operasi aritmetika dasar. Operasi ini dapat dinyatakan dalam dua TFN sebagai berikut: jika $A_{1}=\left(b_{1}, t_{1}, a_{1}\right)$ dan $A_{2}=\left(b_{2}, t_{2}, a_{2}\right)$, sehingga operasi penambahannya dapat ditunjukkan sebagai (3)

$$
A_{1}+A_{2}=\left(b_{1}+b_{2}, t_{1}+t_{2}, a_{1}+a_{2}\right)
$$

operasi pengurangan ditunjukkan pada (4)

$$
A_{1}-A_{2}=\left(b_{1}-a_{2}, t_{1}-t_{2}, a_{1}-b_{2}\right)
$$

operasi pembagian jika $r$ merupakan bilangan nyata ditunjukkan pada (5)

$$
\frac{A_{1}}{r}=\left(\frac{b_{1}}{r}, \frac{t_{1}}{r}, \frac{a_{1}}{r}\right)
$$

operasi perkalian ditunjukkan pada (6)

$$
A_{1} x A_{2}=\frac{1}{6}\left(b_{1}+4 t_{1}+a_{1}\right) x \frac{1}{6}\left(b_{2}+4 t_{2}+a_{2}\right)
$$

total perception dinyatakan dalam (7)

$$
T P e_{i n}=\sum_{1}^{N} P e_{i n}
$$

total expectation dinyatakan dalam (8)

$$
T E x_{i n}=\sum_{1}^{N} E x_{i n}
$$

average service quality persepsi dinyatakan dalam (9)

$$
A P e_{i n}=\sum_{1}^{N} \frac{T P e_{i n}}{N}
$$

average service quality ekspektasi dinyatakan dalam (10)

$$
A E x_{i n}=\sum_{1}^{N} \frac{T E x_{i n}}{N}
$$

dan gap antara average service quality persepsi dan average service quality ekspektasi ditunjukkan dalam (11)

$$
G_{n}=A P e_{n}-A E X_{n}
$$

Gbr. 2 Menunjukkan tampilan awal dari mata kuliah mahasiswa yang diprogram pada semester yang berlangsung. Pada tampilan juga terdapat informasi lainnya yang dibutuhkan oleh mahasiswa, seperti jadwal kuliah, pengumuman terkini, dan rekapitulasi data lainnya.

\section{METODE}

Pengembangan instrumen pada kuesioner didasarkan pada metode service quality [21]. Metode service quality tersebut mengacu pada lima dimensi layanan. Pengembangan indikator atau item pertanyaan mengacu pada kelima dimensi service quality. Tabel I menunjukkan pengembangan indikator dari lima dimensi service quality untuk menilai layanan sistem informasi akademik sebuah PTN di Surabaya yang dinamakan SIAKADU.

Pada pengisian kuesioner digunakan metode fuzzy yang menggunakan pendekatan lingusitik atau lebih dikenal dengan istilah fuzzy linguistic. Penggunaan fuzzy linguistic pada makalah ini bertujuan agar responden dapat memberikan penilaiannya lebih sesuai dengan preferensi masing-masing. Fuzzy linguistic ini terdiri atas tujuh skala, yaitu Sangat Amat Penting (SAP), Sangat Penting (SP), Cukup Penting (CP), Sama Pentingnya (SPa), Kurang Penting (KP), Sangat Kurang Penting (SKP), dan Sangat Amat Kurang Penting (SAKP). Tabel II menunjukkan skala fuzzy linguistic dan fungsi keanggotaannya yang menggunakan TFN.

Kuesioner disusun berdasarkan lima dimensi service quality dengan indikator sebanyak 14 item pertanyaan. Tabel III menunjukkan kuesioner service quality pada layanan SIAKADU. Kemudian dilakukan uji coba awal terhadap kuesioner untuk mengetahui validitas dan reliabilitasnya. Kuesioner ini diujicobakan kepada 30 responden yang keseluruhannya terdiri atas mahasiswa pada Jurusan Informatika Fakultas Teknik pada sebuah PTN di Surabaya untuk mendapatkan nilai validitas dan realibitas. Dengan menggunakan SPSS, hasil uji validitas dapat diketahui.

Tabel IV menunjukkan validitas dari seluruh item pertanyaan. Hasil uji SPSS menunjukkan bahwa nilai hitung korelasi dari item pertanyaan ke-1 sampai dengan item pertanyaan ke-14 lebih besar dari nilai korelasi tabel yaitu 0,361 dengan $N=30$. Oleh karena itu, keempat belas item pertanyaan tersebut dinyatakan valid. 


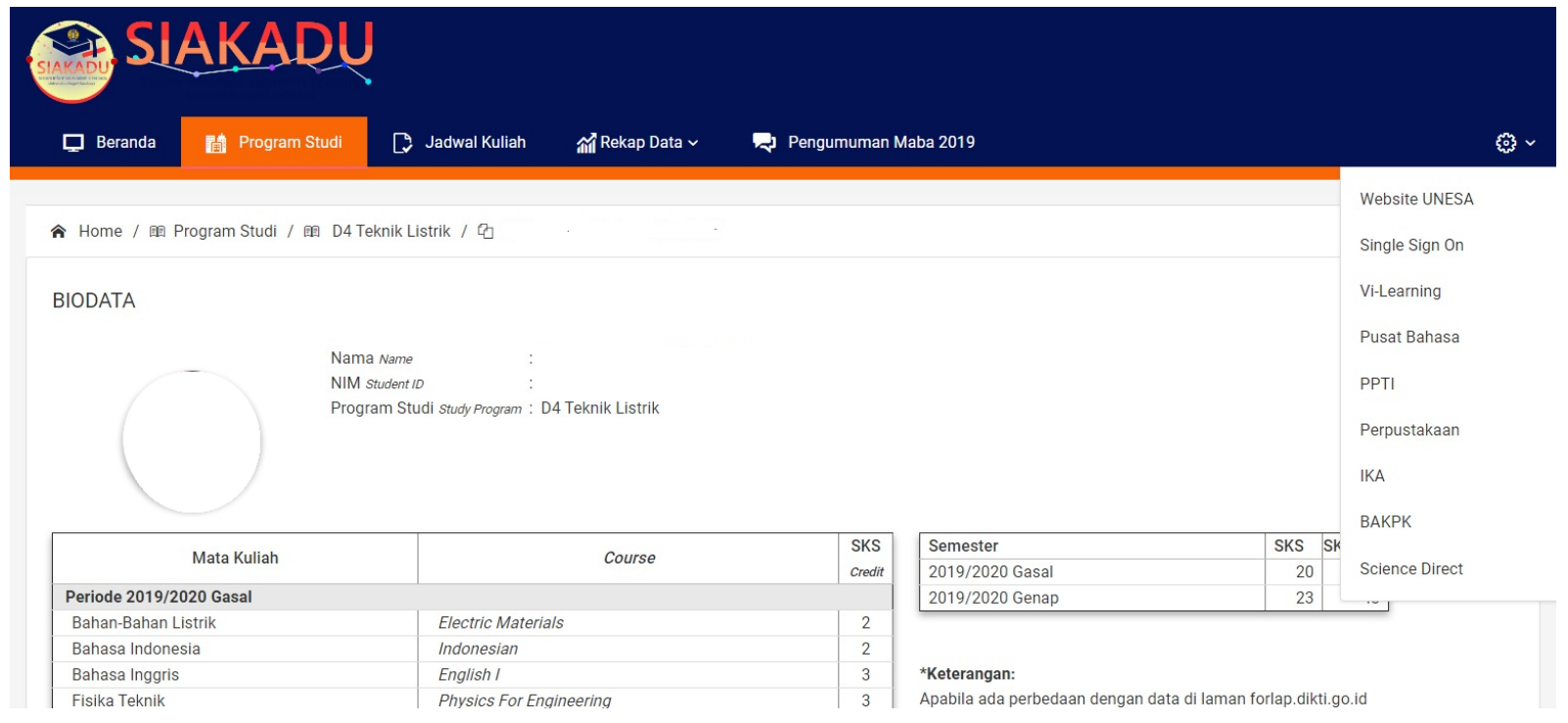

Gbr. 2 Tampilan awal Sistem Informasi Akademik.

TABEL I

DIMENSI DAN INDIKATOR PERTANYAAN PADA INSTRUMEN KUESIONER

\begin{tabular}{|c|c|c|}
\hline Dimensi & No & Indikator \\
\hline \multirow[t]{3}{*}{ Tangible } & 1 & $\begin{array}{l}\text { Tampilan SIAKADU memiliki fitur yang } \\
\text { mudah dipahami }\end{array}$ \\
\hline & 2 & $\begin{array}{l}\text { Sistem SIAKADU dapat diakses di mana } \\
\text { pun dan kapan pun }\end{array}$ \\
\hline & 3 & $\begin{array}{l}\text { Sistem SIAKADU memiliki tampilan } \\
\text { dengan fitur yang sama pada versi mobile } \\
\text { dan web }\end{array}$ \\
\hline \multirow[t]{3}{*}{ Reliability } & 4 & $\begin{array}{l}\text { Sistem SIAKADU tidak memiliki bug } \\
\text { (error) saat diakses }\end{array}$ \\
\hline & 5 & $\begin{array}{l}\text { SIAKADU memiliki sistem informasi } \\
\text { yang bersifat realtime }\end{array}$ \\
\hline & 6 & 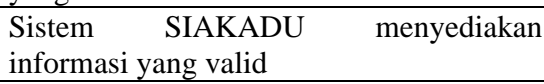 \\
\hline \multirow[t]{3}{*}{ Responsiveness } & 7 & $\begin{array}{l}\text { Fitur-fitur pada sistem SIAKADU telah } \\
\text { berjalan sesuai dengan fungsionalitasnya }\end{array}$ \\
\hline & 8 & $\begin{array}{l}\text { Penanganan error pada sistem SIAKADU } \\
\text { akan dapat diatasi dengan cepat }\end{array}$ \\
\hline & 9 & $\begin{array}{l}\text { Sistem SIAKADU mudah diakses } \\
\text { menggunakan berbagai perangkat, seperti } \\
P C \text {, smartphone, atau tablet }\end{array}$ \\
\hline \multirow[t]{3}{*}{ Assurance } & 10 & $\begin{array}{l}\text { Sistem SIAKADU memiliki sistem } \\
\text { keamanan yang terjamin terhadap data } \\
\text { pengguna }\end{array}$ \\
\hline & 11 & $\begin{array}{l}\text { Sistem SIAKADU yang baik memiliki } \\
\text { user guide atau user manual yang dapat } \\
\text { diakses pengguna }\end{array}$ \\
\hline & 12 & $\begin{array}{l}\text { SIAKADU sudah menjamin privasi dari } \\
\text { setiap penggunanya }\end{array}$ \\
\hline \multirow[t]{2}{*}{ Empathy } & 13 & $\begin{array}{l}\text { SIAKADU menggunakan tata bahasa } \\
\text { mudah dipahami }\end{array}$ \\
\hline & 14 & $\begin{array}{l}\text { SIAKADU memiliki alur yang mudah } \\
\text { dipahami oleh pengguna }\end{array}$ \\
\hline
\end{tabular}

Tahap selanjutnya adalah uji reliabilitas dari kuesioner. Suatu kuesioner dikatakan reliabel/andal jika nilai hitung lebih besar dari nilai tabel. Dengan menggunakan SPSS, dilakukan perhitungan nilai reliabilitas dengan nilai alpha sebesar 5\%.
TABEL II

SKALA PADA FUZZY LINGUISTIC

\begin{tabular}{|l|c|}
\hline \multicolumn{1}{|c|}{ Kategori Linguistik } & $\begin{array}{c}\text { Fungsi } \\
\text { Keanggotaan TFN }\end{array}$ \\
\hline Sangat Amat Penting (SAP) & $(5,6,7)$ \\
\hline Sangat Penting (SP) & $(4,5,6)$ \\
\hline Cukup Penting (CP) & $(3,4,5)$ \\
\hline Sama Pentingnya (SPa) & $(2,3,4)$ \\
\hline Kurang Penting (KP) & $(1,2,3)$ \\
\hline Sangat Kurang Penting (SKP) & $(0,1,2)$ \\
\hline Sangat Amat Kurang Penting (SAKP) & $(0,0,1)$ \\
\hline
\end{tabular}

Hasil uji reliabilitas keseluruhan item pertanyaan menunjukkan angka 0,927, yang berarti lebih besar dari nilai tabel, yaitu 0,361, pada $N=30$. Begitu pula masing-masing dimensi menunjukkan nilai reliabilitas lebih besar dari nilai tabel. Oleh karena itu, hasil uji reliabilitas dari empat belas item pertanyaan dinyatakan reliabel. Tabel $\mathrm{V}$ menunjukkan hasil hitung uji reliabilitas keseluruhan empat belas item pertanyaan.

Pelaksanaan pengambilan data kuesioner dilakukan secara online dan offline. Pelaksanaan pengambilan data secara online dilakukan dengan menyebarkan kuesioner ke alamat $e$ mail mahasiswa dan pelaksanaan pengambilan data secara offline dilakukan secara tatap muka untuk mengisi kuesioner.

Dalam makalah ini, populasi responden adalah seluruh mahasiswa sebuah PTN di Surabaya. Data yang diambil menggunakan metode simple random sampling. Sejumlah 130 kuesioner disebar ke responden. Responden yang mengisi dan mengembalikan kuesioner sebanyak 115 mahasiswa dari berbagai latar belakang fakultas dan angkatan.

\section{HASIL DAN DISKUSI}

Data dari 115 mahasiswa yang diperoleh dari tahap sebelumnya digunakan untuk menghitung nilai persepsi, ekspektasi, dan gap. Perhitungan persepsi, ekspektasi, dan gap dilakukan dengan mengacu pada (3) dan (7), sehingga nilai 
TABEL III

KUESIONER FUZZY SERVICE QUALITY LAYANAN SIAKADU

\begin{tabular}{|l|l|c|}
\hline No & \multicolumn{1}{|c|}{ Pertanyaan } & $\begin{array}{c}\text { Level } \\
\text { Preferensi } \\
\text { (1) - (7) }\end{array}$ \\
\hline 1 & $\begin{array}{l}\text { Seberapa penting tampilan SIAKADU } \\
\text { memiliki fitur yang mudah dipahami? }\end{array}$ & \\
\hline 2 & $\begin{array}{l}\text { Seberapa penting sistem SIAKADU dapat } \\
\text { diakses dimanapun dan kapanpun? }\end{array}$ & \\
\hline 3 & $\begin{array}{l}\text { Seberapa penting sistem SIAKADU memiliki } \\
\text { tampilan dengan memiliki fitur yang sama } \\
\text { pada versi mobile dan web? }\end{array}$ & \\
\hline 4 & $\begin{array}{l}\text { Seberapa penting sistem SIAKADU agar } \\
\text { tidak memiliki bug (error) saat diakses? }\end{array}$ & \\
\hline 5 & $\begin{array}{l}\text { Seberapa penting SIAKADU memiliki sistem } \\
\text { informasi yang bersifat realtime? }\end{array}$ & \\
\hline 6 & $\begin{array}{l}\text { Seberapa penting sistem SIAKADU } \\
\text { menyediakan informasi yang valid? }\end{array}$ & \\
\hline 7 & $\begin{array}{l}\text { Seberapa penting fitur-fitur pada sistem } \\
\text { SIAKADU telah berjalan sesuai dengan } \\
\text { fungsionalitasnya? }\end{array}$ & \\
\hline 8 & $\begin{array}{l}\text { Seberapa penting penanganan error pada } \\
\text { sistem SIAKADU akan dapat diatasi dengan } \\
\text { cepat? }\end{array}$ & \\
\hline 9 & $\begin{array}{l}\text { Seberapa penting sistem SIAKADU agar } \\
\text { mudah diakses menggunakan berbagai } \\
\text { perangkat seperti PC, smartphone, tablet? }\end{array}$ & \\
\hline 10 & $\begin{array}{l}\text { Seberapa penting sistem SIAKADU memiliki } \\
\text { sistem keamanan yang terjamin terhadap data } \\
\text { pengguna? }\end{array}$ & \\
\hline 11 & $\begin{array}{l}\text { Seberapa penting sistem SIAKADU memiliki } \\
\text { user guide atau user manual yang dapat di } \\
\text { akses pengguna? }\end{array}$ & \\
\hline 12 & $\begin{array}{l}\text { Seberapa penting SIAKADU dalam } \\
\text { menjamin privasi dari setiap penggunanya? }\end{array}$ & \\
\hline 13 & $\begin{array}{l}\text { Seberapa penting SIAKADU menggunakan } \\
\text { tata bahasa agar mudah dipahami? }\end{array}$ & \\
\hline 14 & $\begin{array}{l}\text { Seberapa penting SIAKADU memiliki alur } \\
\text { agar mudah dipahami oleh pengguna? }\end{array}$ & \\
\hline
\end{tabular}

Keterangan: (1) Sangat Amat Kurang Penting (SAKP), (2) Sangat Kurang Penting (SKP), (3) Kurang Penting (KP), (4) Sama Pentingnya (SPa), (5) Cukup Penting (CP), (6) Sangat Penting (SP), (7) Sangat Amat Penting (SAP)

persepsi average service quality dari item pertama dari 115 responden adalah

$$
A P e_{1}=(3,59,4,58,5,58) .
$$

Dengan menggunakan (3) dan (8), diperoleh nilai ekspektasi average service quality item pertama dari 115 responden, yaitu

$$
A E_{X}=(3,98 ; 4,95 ; 5,95) .
$$

Perhitungan gap service quality dilakukan dengan menggunakan (4). Untuk item pertama dari responden diperoleh

$$
\begin{aligned}
\text { Fuzzy Gap } & =A P e_{1}-A E x_{1} \\
& =(3,59,4,58,5,58)-(3,98,4,95,5,95) \\
& =(4,00-5,95,4,58-4,95,5,58-3,98) \\
& =(-2,36,-0,37,1,60) .
\end{aligned}
$$

\begin{tabular}{|c|c|c|c|}
\hline $\begin{array}{c}\text { Item } \\
\text { pertanyaan }\end{array}$ & $r_{x y}$ & $\begin{array}{l}\text { rtabel } 5 \% \\
(N=30)\end{array}$ & Keterangan \\
\hline 1 & 0,701 & 0,361 & Valid \\
\hline 2 & 0,481 & 0,361 & Valid \\
\hline 3 & 0,705 & 0,361 & Valid \\
\hline 4 & 0,833 & 0,361 & Valid \\
\hline 5 & 0,651 & 0,361 & Valid \\
\hline 6 & 0,861 & 0,361 & Valid \\
\hline 7 & 0,781 & 0,361 & Valid \\
\hline 8 & 0,670 & 0,361 & Valid \\
\hline 9 & 0,715 & 0,361 & Valid \\
\hline 10 & 0,670 & 0,361 & Valid \\
\hline 11 & 0,871 & 0,361 & Valid \\
\hline 12 & 0,727 & 0,361 & Valid \\
\hline 13 & 0,728 & 0,361 & Valid \\
\hline 14 & 0,842 & 0,361 & Valid \\
\hline
\end{tabular}

TABEL IV

HASIL UJI VALIDITAS ITEM PERTANYAAN PADA LAYANAN SIAKADU

UJI RELIABILITAS KUESIONER LAYANAN SIAKADU

\begin{tabular}{|l|l|c|l|}
\hline \multicolumn{1}{|c|}{ Dimensi } & $\begin{array}{c}\text { Cronbach's Alpha } \\
(\boldsymbol{N}=\text { jumlah item })\end{array}$ & $\begin{array}{c}\text { rtabel 5\% } \\
\mathbf{( 3 0 )}\end{array}$ & Keterangan \\
\hline Tangible & $0,6453(\mathrm{~N}=3)$ & 0,361 & Reliabel \\
\hline Reliability & $0,8259(\mathrm{~N}=3)$ & 0,361 & Reliabel \\
\hline Responsiveness & $0,7600(\mathrm{~N}=3)$ & 0,361 & Reliabel \\
\hline Assurance & $0,7961(\mathrm{~N}=3)$ & 0,361 & Reliabel \\
\hline Empathy & $0,9268(\mathrm{~N}=2)$ & 0,361 & Reliabel \\
\hline Keseluruhan & $0,927(\mathrm{~N}=14)$ & 0,361 & Reliabel \\
\hline
\end{tabular}

Selanjutnya dapat dihitung nilai $\mathrm{Gap}_{1}$ sebagai berikut.

$$
\begin{aligned}
\text { Gap }_{1} & =1 / 6 \times(-2,36+4 \times-0,37 \times 1,60) \\
& =-0,373 .
\end{aligned}
$$

Dengan menggunakan (2), yaitu graded mean integration, diperoleh hasil perhitungan untuk gap item 1 (Gap 1$)$ yaitu sebesar -0,373. Hasil perhitungan menunjukkan nilai gap bertanda negatif, yang berarti responden belum puas terhadap item service quality ini. Demikian pula untuk penggunaan (2) untuk menghitung nilai $A P e_{1}$ sebesar 4,58 dan nilai $A E x_{1}$ sebesar 4,96. Hasil seluruh perhitungan item dari masingmasing dimensi service quality disajikan dalam Tabel VI. Hasil perhitungan menunjukkan bahwa seluruh nilai gap menunjukkan tanda negatif. Hal ini menunjukkan bahwa layanan yang disediakan masih belum memenuhi ekspektasi pengguna. Untuk ekspektasi pada dimensi service quality, nilai tertinggi adalah pada dimensi empathy sebesar 5,47, dikuti oleh responsiveness sebesar 5,45, reliability sebesar 5,21, assurance sebesar 5,13, dan tangible sebesar 5,02. Sedangkan untuk persepsi pada dimensi service quality, nilai tertinggi adalah pada dimensi empathy sebesar 4,77, dikuti oleh responsiveness sebesar 4,55, tangible sebesar 4,33, assurance sebesar 4,30, dan reliability sebesar 4,20.

Sesuai dengan persepsi pengguna SIAKADU berkaitan dengan dimensi tangible, item 2 (Seberapa penting sistem SIAKADU dapat diakses di mana pun dan kapan pun?) mempunyai nilai tertinggi sebesar 4,62, diikuti oleh item 1 (Seberapa penting tampilan SIAKADU memiliki fitur yang mudah dipahami?) sebesar 4,58, dan yang paling rendah 
TABEL VI

NILAI DARI FUZZY PERSEPSI, EKSPEKTASI, DAN GAP

\begin{tabular}{|c|c|c|c|}
\hline Dimensi & Fuzzy Persepsi & Fuzzy Ekspektasi & Fuzzy Gap \\
\hline Tangible & $(3,35,4,33,5,33)$ & $(4,03,5,01,6,01)$ & $(-2,66,-0,69,1,30)$ \\
\hline 1 & $(3,59,4,58,5,58)$ & $(3,98,4,95,5,95)$ & $(-2,36,-0,37,1,60)$ \\
\hline 2 & $(3,63,4,62,5,62)$ & $(4,06,5,06,6,06)$ & $(-2,43,-0,44,1,56)$ \\
\hline 3 & $(2,84,3,78,4,78)$ & $(4,05,5,03,6,03)$ & $(-3,19,-1,25,0,73)$ \\
\hline Reliability & $(3,24,4,19,5,19)$ & $(4,22,5,21,6,21)$ & $(-2,97,-1,02,0,97)$ \\
\hline 4 & $(2,76,3,68,4,68)$ & $(4,17,5,15,6,15)$ & $(-3,39,-1,47,0,51)$ \\
\hline 5 & $(3,17,4,12,5,12)$ & $(3,98,4,97,5,97)$ & $(-2,80,-0,85,1,14)$ \\
\hline 6 & $(3,79,4,77,5,77)$ & $(4,50,5,50,6,50)$ & $(-2,71,-0,73,1,27)$ \\
\hline Responsiveness & $(3,58,4,54,5,54)$ & $(4,45,5,45,6,45)$ & $(-2,87,-0,91,1,09)$ \\
\hline 7 & $(3,61,4,57,5,57)$ & $(4,38,5,38,6,38)$ & $(-2,77,-0,81,1,19)$ \\
\hline 8 & $(3,72,4,70,5,70)$ & $(4,52,5,52,6,52)$ & $(-2,80,-0,82,1,18)$ \\
\hline 9 & $(3,42,4,35,5,35)$ & $(4,46,5,46,6,46)$ & $(-3,04,-1,11,0,89)$ \\
\hline Assurance & $(3,33,4,30,5,30)$ & $(4,14,5,13,6,13)$ & $(-2,80,-0,83,1,15)$ \\
\hline 10 & $(3,16,4,14,5.14)$ & $(3,83,4,80,5,80)$ & $(-2,64,-0,66,1,31)$ \\
\hline 11 & $(3,24,4,20,5.20)$ & $(4,10,5,09,6,09)$ & $(-2,85,-0,89,1,10)$ \\
\hline 12 & $(3,58,4,55,5.55)$ & $(4,50,5,50,6,50)$ & $(-2,92,-0,95,1,05)$ \\
\hline Empathy & $(3,78,4,77,5.77)$ & $(4,47,5,47,6,47)$ & $(-2,69,-0,71,1,30)$ \\
\hline 13 & $(3,93,4,92,5.92)$ & $(4,48,5,48,6,48)$ & $(-2,55,-0,56,1,44)$ \\
\hline 14 & $(3,63,4,61,5.61)$ & $(4,46,5,46,6,46)$ & $(-2,83,-0,85,1,15)$ \\
\hline
\end{tabular}

adalah item 3 (Seberapa penting sistem SIAKADU memiliki tampilan dengan memiliki fitur yang sama pada versi mobile dan web?), yaitu sebesar 3,79.

Untuk dimensi reliability, item 6 (Seberapa penting sistem SIAKADU menyediakan informasi yang valid?) mempunyai nilai tertinggi sebesar 4,77, diikuti oleh item 5 (Seberapa penting SIAKADU memiliki sistem informasi yang bersifat realtime?) sebesar 4,13, dan yang paling rendah adalah item 4 (Seberapa penting sistem SIAKADU agar tidak memiliki bug (error) saat diakses?), yaitu sebesar 3,69.

Untuk dimensi responsiveness, item 8 (Seberapa penting penanganan error pada sistem SIAKADU akan dapat diatasi dengan cepat?) mempunyai nilai tertinggi sebesar 4,70, diikuti oleh item 7 (Seberapa penting fitur-fitur pada sistem SIAKADU telah berjalan sesuai dengan fungsionalitasnya?) sebesar 4,58, dan yang paling rendah adalah item 9 (Seberapa penting sistem SIAKADU agar mudah diakses menggunakan berbagai perangkat seperti $P C$, smartphone, tablet?), yaitu sebesar 4,36.

Untuk dimensi assurance, item 12 (Seberapa penting SIAKADU dalam menjamin privasi dari setiap penggunanya?) mempunyai nilai tertinggi sebesar 4,56, diikuti oleh item 11 (Seberapa penting sistem SIAKADU memiliki user guide atau user manual yang dapat di akses pengguna?) sebesar 4,21, dan yang paling rendah adalah item 10 (Seberapa penting sistem SIAKADU memiliki sistem keamanan yang terjamin terhadap data pengguna?), yaitu sebesar 4,14.
Untuk dimensi empathy, item 13 (Seberapa penting SIAKADU menggunakan tata bahasa agar mudah dipahami?) mempunyai nilai tertinggi sebesar 4,56 dan yang paling rendah adalah item 14 (Seberapa penting SIAKADU memiliki alur agar mudah dipahami oleh pengguna?), yaitu sebesar 4,61.

Urutan lima gap tertinggi pada keempat belas item antara persepsi dan ekspektasi adalah pada item 4 (Seberapa penting sistem SIAKADU agar tidak memiliki bug (error) saat diakses?) sebesar -1,460, kemudian diikuti secara berurutan oleh item 3 (Seberapa penting sistem SIAKADU memiliki tampilan dengan memiliki fitur yang sama pada versi mobile dan web?) sebesar -1,243, item 9 (Seberapa penting sistem SIAKADU agar mudah diakses menggunakan berbagai perangkat seperti $P C$, smartphone, tablet?) sebesar -1,098, item 12 (Seberapa penting SIAKADU dalam menjamin privasi dari setiap penggunanya?) sebesar -0,945, dan item 11 (Seberapa penting sistem SIAKADU memiliki user guide atau user manual yang dapat di akses pengguna?) sebesar -0,885.

Urutan lima gap terendah pada keempat belas item antara persepsi dan ekspektasi adalah pada item 1 (Seberapa penting tampilan SIAKADU memiliki fitur yang mudah dipahami?) sebesar -0,373, kemudian diikuti secara berurutan oleh item 2 (Seberapa penting sistem SIAKADU dapat diakses di mana pun dan kapan pun?) sebesar -0,438, item 13 (Seberapa penting SIAKADU menggunakan tata bahasa agar mudah dipahami?) sebesar -0,558, item 10 (Seberapa penting sistem SIAKADU memiliki sistem keamanan yang terjamin terhadap 
TABEL VII

NILAI PERSEPSI, EKSPEKTASI, DAN GAP

\begin{tabular}{|l|l|l|l|}
\hline \multicolumn{1}{|c|}{ Dimensi } & \multicolumn{1}{c|}{ Persepsi } & \multicolumn{1}{|c|}{ Ekspektasi } & Gap \\
\hline Tangible & $\mathbf{4 , 3 3}$ & $\mathbf{5 , 0 2}$ & $\mathbf{- 0 , 6 8 5}$ \\
\hline 1 & 4,58 & 4,96 & $-0,373$ \\
\hline 2 & 4,62 & 5,06 & $-0,438$ \\
\hline 3 & 3,79 & 5,03 & $-1,243$ \\
\hline Reliability & $\mathbf{4 , 2 0}$ & $\mathbf{5 , 2 1}$ & $\mathbf{- 1 , 0 1 0}$ \\
\hline 4 & 3,69 & 5,15 & $-1,460$ \\
\hline 5 & 4,13 & 4,97 & $-0,843$ \\
\hline 6 & 4,77 & 5,50 & $-0,727$ \\
\hline Responsiveness & $\mathbf{4 , 5 5}$ & $\mathbf{5 , 4 5}$ & $\mathbf{- 0 , 9 0 6}$ \\
\hline 7 & 4,58 & 5,38 & $-0,803$ \\
\hline 8 & 4,70 & 5,52 & $-0,817$ \\
\hline 9 & 4,36 & 5,46 & $-1,098$ \\
\hline Assurance & $\mathbf{4 , 3 0}$ & $\mathbf{5 , 1 3}$ & $\mathbf{- 0 , 8 3 1}$ \\
\hline 10 & 4,14 & 4,81 & $-0,662$ \\
\hline 11 & 4,21 & 5,09 & $-0,885$ \\
\hline 12 & 4,56 & 5,50 & $-0,945$ \\
\hline Empathy & $\mathbf{4 , 7 7}$ & $\mathbf{5 , 4 7}$ & $\mathbf{- 0 , 7 0 3}$ \\
\hline 13 & 4,92 & 5,48 & $-0,558$ \\
\hline 14 & 4,61 & 5,46 & $-0,847$ \\
\hline & & &
\end{tabular}

data pengguna?) sebesar -0,662, item 6 (Seberapa penting sistem SIAKADU menyediakan informasi yang valid?) sebesar $-0,727$.

Nilai rata-rata gap service quality antara nilai rata-rata persepsi dan nilai rata-rata ekspektasi dari masing-masing dimensi ditunjukkan pada Tabel VII. Seluruh rata-rata gap service quality bertanda negatif. Gap service quality bertanda negatif menunjukkan bahwa pada dimensi tersebut layanan dirasakan kurang memuaskan oleh pengguna layanan [15]. Gap service quality bernilai negatif terbesar adalah pada dimensi reliability yaitu sebesar -1,010, yang menunjukkan bahwa keandalan secara realtime dan penyediaan informasi masih dirasakan kurang oleh pengguna. Kemudian, gap service quality responsiveness adalah sebesar -0,906, yang menunjukkan bahwa fitur-fitur yang disediakan pada format PC ataupun tablet dan smartphone masih ada yang tidak sama atau sesuai dengan fungsinya. Gap service quality assurance sebesar -0,831 menunjukkan bahwa pengguna merasakan keamanan dari sistem akademik ini masih perlu ditingkatkan agar dapat menjamin keamanan data dan privasi pengguna. Selanjutnya, gap service quality empathy sebesar -0,703 menunjukkan masih ada alur informasi pada sistem informasi akademis yang sulit dipahami atau membingungkan pengguna. Terakhir, gap service quality tangible adalah sebesar -0,685, yang menunjukkan masih sulitnya untuk akses di daerah mana pun dan masih ada beda fitur antara versi mobile dan web yang dirasakan oleh pengguna.

\section{KESIMPULAN}

Hasil penelitian berkontribusi pada penerapan fuzzy service quality dengan menggunakan preferensi tujuh tingkatan yang digunakan untuk menentukan tingkat kepuasan pengguna terhadap layanan sistem informasi akademik pada suatu PTN di Surabaya. Hasil penelitian juga berkontribusi dalam mengembangkan instrumen kuesioner untuk mengakses kelima dimensi service quality pada layanan sistem informasi akademik pada suatu PTN.

Hasil menunjukkan bahwa metode fuzzy service quality mampu menganalisis gap yang terjadi pada kelima dimensi service quality melalui indikator-indikatornya, sehingga dapat diketahui masing-masing gap yang terjadi, bernilai positif atau negatif. Hasil perhitungan menunjukkan bahwa gap service quality dari masing-masing dimensi antara nilai rata-rata persepsi dan nilai rata-rata ekspektasi dari yang terbesar adalah pada dimensi reliability yaitu sebesar -1,010, kemudian diikuti secara berurutan oleh responsiveness sebesar -0,906, assurance sebesar -0,831, empathy sebesar -0,703, dan tangible sebesar -0,685. Selanjutnya, para pengambil keputusan dapat memperbaiki dimensi service quality dengan nilai gap terbesar untuk diperbaiki. Dengan melakukan quality improvement secara terus-menerus, diharapkan layanan dapat meningkat menjadi lebih baik.

\section{REFERENSI}

[1] N.M Stefano, N.C. Filho, R. Barichello, dan A.P. Sohn, “A Fuzzy SERVQUAL Based Method for Evaluated of Service Quality in the Hotel Industry,” Procedia CIRP, Vol. 30, hal. 433 - 438, 2015.

[2] J.T. Fragoso dan I.L. Espinoza, “Assessment of Banking Service Quality Perception Using the SERVPERF Model,” Contaduría y Administración, Vol. 62, No. 4, hal. 1294-1316, 2017.

[3] U.A. Qadri., "Measuring Service Quality Expectation and Perception Using SERVQUAL: A Gap Analysis,” Bussiness Economy Journal, Vol. 6, No. 3, hal. 1-6, 2015.

[4] M. Ali dan S.A. Raza, "Service Quality Perception and Customer Satisfaction in Islamic Banks of Pakistan: The Modified SERVQUAL Model,” Total Quality Management \& Business Excellence, Vol. 28, No. 5-6, hal. 559-577, 2017.

[5] H.S. Al-Neyadi, S. Abdallah, dan M. Malik, "Measuring Patient's Satisfaction of Healthcare Services in the UAE Hospitals: Using SERVQUAL," International Journal of Healthcare Management, Vol. 11, No. 2, hal. 95-105, 2018.

[6] L.H. Ho, S.Y. Feng, dan T.M. Yen, "Using Fuzzy Gap Analysis to Measure Medical Tourism Service Quality,” International Journal of Health Care Quality Assurance, Vol. 28, No. 7, hal. 648-659, 2015.

[7] I. Blešiæ, I. Dzigurski, A. Stankov, U. Stamenkoviæ, dan I. Bradiæ, "Research of Expected and Perceived Service Quality in Hotel Management. Revista de Turism: Studii si Cercetari in Turism,” Journal of Tourism - Studies and Research in Tourism, Vol. 11, No. 11, hal. 614, 2011.

[8] L. Ren, H. Qiu, P. Wang, dan P.M.C. Lin, "Exploring Customer Experience with Budget Hotels: Dimensionality and Satisfaction," International Journal of Hospitality Management, Vol. 52, hal. 1323, 2016.

[9] M.S. Alam dan M. Mondal, “Assessment of Sanitation Service Quality in Urban Slums of Khulna City Based on SERVQUAL and AHP Model: A Case Study of Railway Slum, Khulna, Bangladesh,” Journal of Urban Management, Vol. 8, No. 1, hal. 20-27, 2019.

[10] M.M. Pandey, "Evaluating the Service Quality of Airports in Thailand Using Fuzzy Multi-Criteria Decision Making Method," Journal of Air Transport Management, Vol. 57, hal. 241-249, 2016.

[11] I.G.K.T.P. Budhi dan N.K. Sumiari, "Pengukuran Customer Satisfaction Index Terhadap Pelayanan di Century Gym," Jurnal Ilmiah SISFOTENIKA, Vol. 7, No. 1, hal. 25-37, 2017.

[12] R. Jamali dan H.S. Tooranloo, "Prioritizing Academic Library Service Quality Indicators Using Fuzzy Approach Case Study: Libraries of Ferdowsi University,” Library Management, Vol. 30, No. 4/5, hal. 319333, 2009. 
[13] V. Teeroovengadum, T.J. Kamalanabhan, dan A.K. Seebaluck, "Measuring Service Quality in Higher Education," Quality Assurance in Education, Vol. 24, No. 2, hal. 244 - 258, 2016.

[14] S. Ada, Z.N. Baysal, dan S.S.Ș. Erkan, "An Evaluation of Service Quality in Higher Education: Marmara and Niğde Omer Halisdemir Universities' Department of Education Students," Universal Journal of Educational Research, Vol. 5, No. 11, hal. 2056-2065, 2017.

[15] S. Behdioğlu, E. Acar, dan H.A. Burhan, "Evaluating Service Quality by Fuzzy SERVQUAL: A Case Study in a Physiotherapy and Rehabilitation Hospital," Total Quality Management \& Business Excellence, Vol. 30, No. 3-4, hal. 301-319, 2017.

[16] L. Abdullah dan S. Khadiah, "Fuzzy Linguistic for Measuring Customer Satisfaction," International Journal of Latest Trends in Computing, Vol. 2, No. 2, hal. 220-224, 2011.

[17] H.T. Lin, "Fuzzy Application in Service Quality Analysis: An Empirical Study," Expert Systems with Applications, Vol. 37, No. 1, hal. 517-526, 2010.
[18] C.C. Choua, L.J. Liub, S.F. Huangc, J.M. Yihd, dan T.C. Han, "An Evaluation of Airline Service Quality Using the Fuzzy Weighted SERVQUAL Method," Applied Soft Computing, Vol. 11, No. 2, hal. 2117-2128, 2011.

[19] V. Charles, M. Kumar, dan S. Suggu, "Adapting Fuzzy Linguistic Servqual Model: A Comparative Analysis of Bank Services," MiddleEast Journal of Scientific Research, Vol. 18, No. 8, hal. 1119-1132, 2013.

[20] R. Liu, L. Cui, G. Zeng, H. Wu, C. Wang, S. Yan, dan B. Yan, "Applying the Fuzzy SERVQUAL Method to Measure the Service Quality in Certification \& Inspection Industry," Applied Soft Computing, Vol. 26, hal. 508-512, 2015.

[21] A.P. Parasuraman, V.A. Zeithaml, dan L.L. Berry, "SERVQUAL: A Multiple-Item Scale for Measuring Consumer Perceptions of Service Quality,' Journal of Retailing, Vol. 64, No. 1, hal. 12-40, 1988 